\title{
Sistem Retensi dan Alih Image Rekam Medis Inaktif RS Khusus Kanker MRCCC Siloam Semanggi
}

\author{
Sudjiran ${ }^{1}$, Akbar Syahbanta Limbong ${ }^{2}$ \\ ${ }^{1,2}$ Sistem Informasi, STMIK Jakarta STI\&K, Jl. BRI Radio Dalam No. 17, Jakarta Selatan \\ e-mail: ${ }^{1}$ ontosenosudjiran@gmail.com, ${ }^{2}$ akbar_limbong@gmail.com
}

Submitted Date: February $23^{\text {rd }}, 2021$

Revised Date: June 04 ${ }^{\text {th }}, 2021$
Reviewed Date: June 02 nd 2021

Accepted Date: June $15^{\text {th }}, 2021$

\begin{abstract}
Along with the development of technology, the speed of data processing is needed in order to compete with competitors. A company must have an advantage over other companies if it does not want to lose in the competition. MRCCC Siloam Semanggi is a company that provides health services for cancer patients. One of the transaction processes within the hospital is sensing data in the form of images of patient data. Image data processing activities at this hospital are not yet structured and require a database in order to assist in fast data processing. This study aims to create an image transfer system to transfer physical documents into digital documents. This system is useful for hospital employees to be able to find documents easily for certain purposes, the system is made web-based using XAMPP, using PHP language with MySQL database. The results of the analysis of research that has been done, there are problems that arise related to the retention system in hospital patient data. Retention data collection activities are usually carried out by sorting out patient medical record documents from those not recorded on a computer.
\end{abstract}

Keywords: System; Retention; Image Transfer; Medical Record; PHP; Web

\section{Abstrak}

Seiring dengan perkembangan teknologi kecepatan pengelolahan data di perlukan agar dapat bersaing dengan pesaing. Sebuah perusahaan harus harus memeiliki keunggulan dari perusahaan lain jika tidak mau kalah dalam persaiangan. MRCCC Siloam Semanggi adalah perusahan yang menyediaan jasa pelayanan kesehatan bagi penderita kanker. Salah satu proses transaksi didalam rumah sakit adalah data pengindraan berupa gambar data pasien. Kegiataan pengolahan data gambar pada rumah sakit ini belum terstruktur dan memerlukan database agar dapat membantu dalam pengolahan data secara cepat. Penelitian ini bertujuan membuat sistem alih image untuk memindahkan dokumen fisik menjadi dokumen digital. Sistem ini berguna untuk para pegawai rumah sakit agar dapat mencari dokumen dengan mudah untuk kepentingan tertentu, sistem dibuat berbasis web dengan menggunakan XAMPP, menggunakan bahasa PHP dengan database MySQL. Hasil analisa penelitian yang sudah dilakukan, ada masalah-masalah timbul berhubungan dengan sistem retensi pada data pasien rumah sakit. Kegiatan pendataan retensi biasanya dilakukan dengan memilah dokumen rekam medis pasien dan tidak tercatat komputer.

Kata Kunci: Sistem; Retensi; Alih Image; Rekam Medis; PHP; Web

\section{Pendahuluan}

Rumah Sakit Khusus Kanker MRCCC Siloam Semanggi merupakan salah satu rumah sakit khusus kanker yang memiliki sarana dan prasarana yang baik serta berkualitas. Rumah sakit adalah organisasi sosial kesehatan dengan fungsi pelayanan kesehatan seperti penyembuhan dan pencegahan penyakit masyarakat umum. Setiap harinya rumah sakit mendapatkan banyak pasien baru yang berdatangan untuk periksa kesehatan sehingga dalam hal membuat arsip di Rumah Sakit Khusus Kanker MRCCC Siloam Semanggi semakin banyak, sehingga diperlukan suatu pengelolaan arsip yang baik dan dapat dilakukan melalui proses penyusutan arsip berdasarkan metode jadwal retensi arsip.

Arsip yang berada pada Rumah Sakit Khusus Kanker MRCCC Siloam Semanggi 
merupakan arsip yang sangat penting karena arsip tersebut memuat tentang rekam medis para pasien sehingga dalam hal ini perlu dilakukan retensi atau penyusutan arsip dengan benar sehingga terwujudnya pelayanan yang lancar untuk setiap pasien, dengan adanya pengelolaan arsip yang baik maka pegawai administrasi tidak akan mengalami kesulitan-kesulitan dalam menangani pasien. Rumah Sakit Khusus Kanker MRCCC Siloam Semanggi belum menggunakan database untuk melakukan retensi file. Belum adanya sistem yang digunakan untuk menyimpan berkas-berkas file rekam medis mengakibatkan menumpuknya filefile pada ruangan filling. Sistem yang digunakan dapat memakan waktu yang lama dan kurang efektif. Terjadi penumpukan berkas yang diinput dikarenakan lamanya waktu pengerjaan setiap berkas rekam medis yang retensi secara manual.

Saat ini perkembangan teknologi informasi semakin pesat yang sifatnya flexibel terutama dalam menjalankan proses bisnis pada berbagai bidang salah satunya pada bidang kesehatan yang ada di rumah sakit. Sangat penting bagi rumah sakit membangun sistem komputerisasi yang dapat membantu dalam mempercepat proses pekerjaan

Berdasarkan permasalahan tersebut agar proses retensi atau pemusnahan arsip berjalan dengan cepat dan efisien diperlukan suatu sistem pendukung solusi masalah tersebut.

\section{Analisa Masalah}

Memahami pengertian sistem retensi dan alih image rekam medis inaktif, terlebih dahulu dijelaskan pengertian masing-masing. Sistem merupakan jaringan kerja dari banyak prosedur yang bekerjasama melakukan kegiatan dengan sasaran sudah ditentukan.

Retensi merupakan kegiatan pengurangan dokumen rekam medis pada penyimpanan dengan menentukan formulir yang masih berguna. Alih Image adalah usaha merubah bentuk media informasi tercetak ke bentuk data perangkat lunak.

Pengalih image merupakan kegiatan pemindahan informasi ke media yang lebih efisien dan efektif. Dokumen rekam medis berisi data identitas pasien beserta data proses lengkap pelayanan kesehatan. Dokumen ini juga berisi laporan dokter tentang hasil penanganan kepada pasien.

Rumah sakit adalah institusi pelayanan kesehatan perseorangan secara promotif, preventif, kuratif dan rehabilitative dengan pelayanan rawat inap, rawat jalan dan gawat darurat. RS. Khusus Kanker MRCCC Siloam Semanggi dalam kegiatannya belum menggunakan database untuk melakukan retensi file. belum adanya sistem yang digunakan untuk menyimpan berkas-berkas file rekam medis yang mengakibatkan menumpuknya file-file pada ruangan filing. Pengolahan kegiatan retensi disimpan dalam dokumen-dokumen diubah kedalam sistem komputerisasi karena sistem yang masih manual memakan waktu yang lama dan kurang efektif. Hal ini dapat mengakibatkan terjadinya penumpukan berkas yang diinput dikarenakan lamanya waktu pengerjaan setiap berkas rekam medis yang diretensi secara manual. Sehingga terdapat pekerjaan yang lain juga menjadi terhambat dalam pengerjaannya

\section{Perancangan Sistem}

Perancangan sistem dilakukan setelah kegiatan analisis. Perancangan dikerjakan berguna untuk penggambaran, perancangan, dan pembuatan sketsa suatu kegiatan menjadi satu kesatuan yang utuh dan berfungsi.

Kegiatan perancangan sistem yang menggunakan semua data masukan dan keluaran dari sistem. Penggambaran tersebut dapat menggunakan diagram konteks. Berikut ini diagram Sistem Retensi dan Alih Image Rekam Medis Inaktif pada Rumah Sakit Khusus Kanker MRCCC Siloam Semanggi.

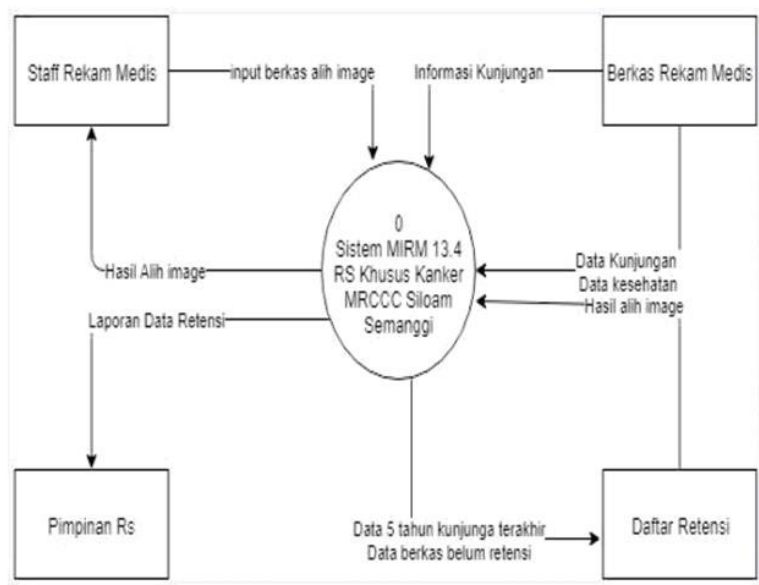

Gambar 1. Diagram Kontek Sistem

Pada gambar 1 merupakan gambar diagram kontek sistem yang dirancang dalam penelitian ini. Diagram ini menjelaskan sistem secara keseluruhan dengan beberapa terminator sebagai objek pengguna sistem.

Diagram alur data menggambarkan aliran transformasi data dan informasi dari keluar dan masuknya ke suatu sistem. Diagram aliran data dapat membantu pengguna sistem yang kurang 
menguasai sistem komputer menjadi lebih paham. Diagram akur pada penelitian ini sebagai begikut.

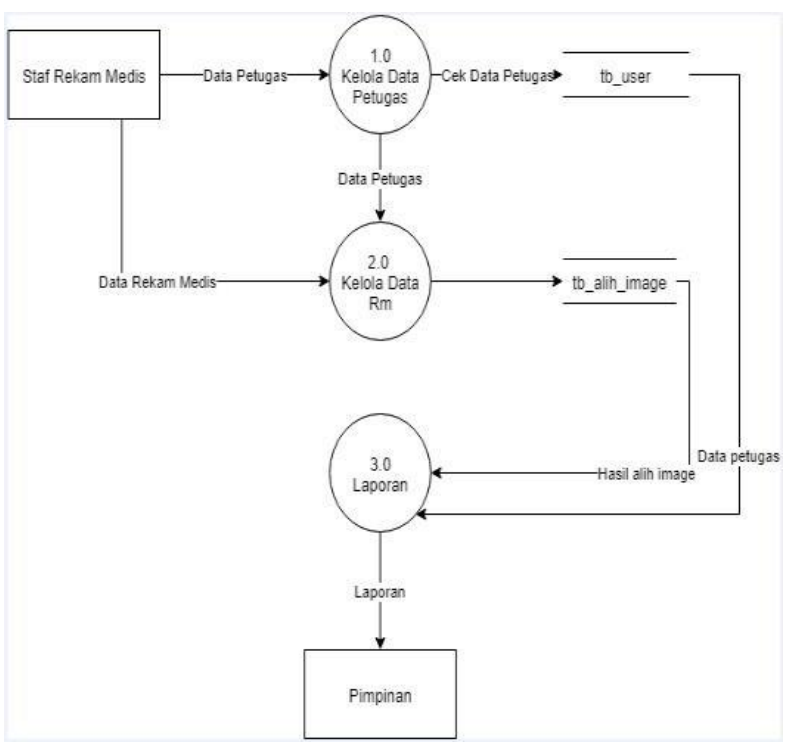

Gambar 2. Diagram Alur Data Sistem.

Pada Gambar 2 merupakan gambar kontek sistem yang di rancang dalam penelitian ini. Diagram ini menjelaskan secara detail alur bisnis proses sistem yang pada intinya menghasilkan sejumlah data store untuk diagram ER.

Diagram Keterhubungan entitas merupakan model relasi berupa susunan data tersimpan secara abstrak pada suatu sistem. Berisi komponenkomponen jaringan dan himpunan entitas dan relasi memiliki atribut-atribut.

Berikut adalah diagram dari Sistem Retensi dan Alih Image Rekam Medis Inaktif di Rumah Sakit Khusus Kanker MRCCC Siloam Semanggi

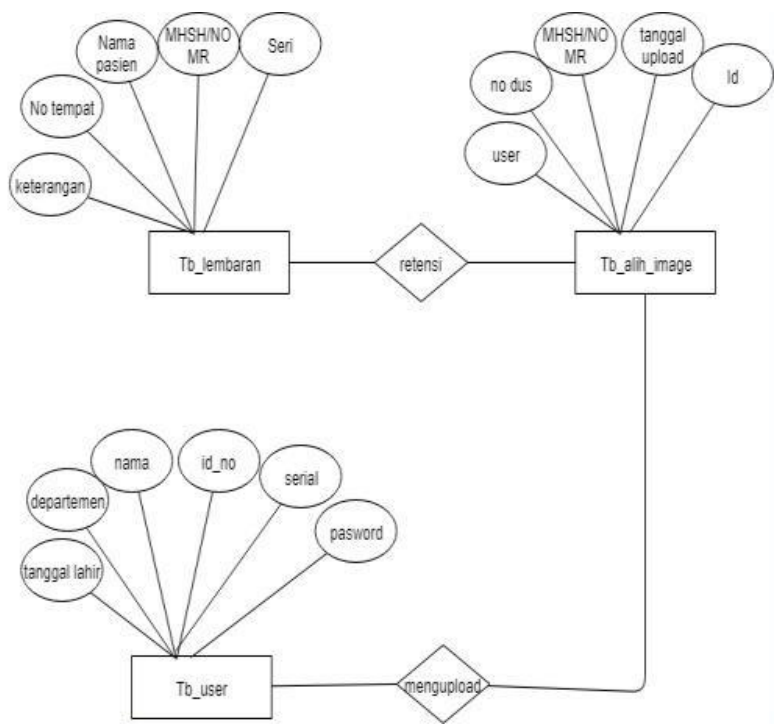

Gambar 3. Diagram ER Sistem RS.
Pada gambar 3 merupakan diagram keterhubungan antar entitas. Diagram ini merupakan transformasi dari data store yang di hasilkan dari rancangan diagram kontek. Elemen entititas dan relasi di rubah menjadi tabel-tabel pada database.

Struktur menu merupakan perancangan program menjadi lebih terstruktur dalam penggunaannya menjadi lebih mudah.

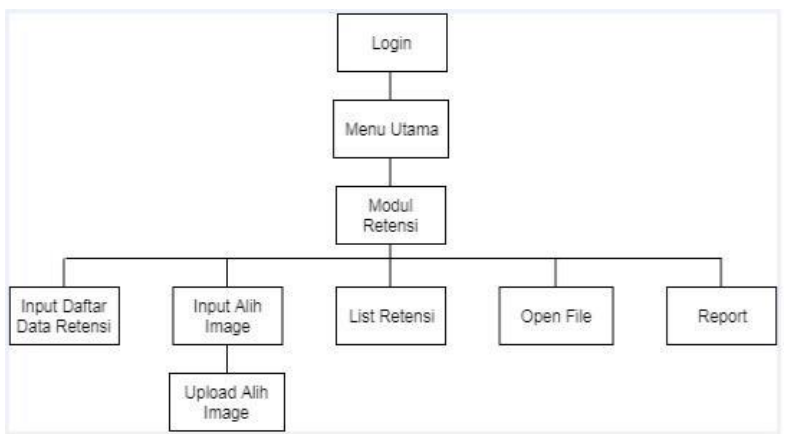

Gambar 4. Struktur Menu Sistem

Pada gamabr 4 adalah gambaran struktur menu sistem. Struktur menu ini berisi perintahperintah yang tersedia pada sistem. Setiap pengguna akan mendapatkan akses untuk menjalankan perintah sesuai hak akses masingmasing.

\section{Implementasi Sistem}

Tahapan berikutnya adalah implementasi sistem. Kegiatan implementasi sistem ini dilakukan setelah didesain ke dalam pemrograman komputer. Program komputer ini dibuat berdasarkan kebutuhan sesuai analisis. Proses dari tahapan implementasi berupa urutan kegiatan awal sampai akhir sampai terwujud sistem yang telah dirancang.

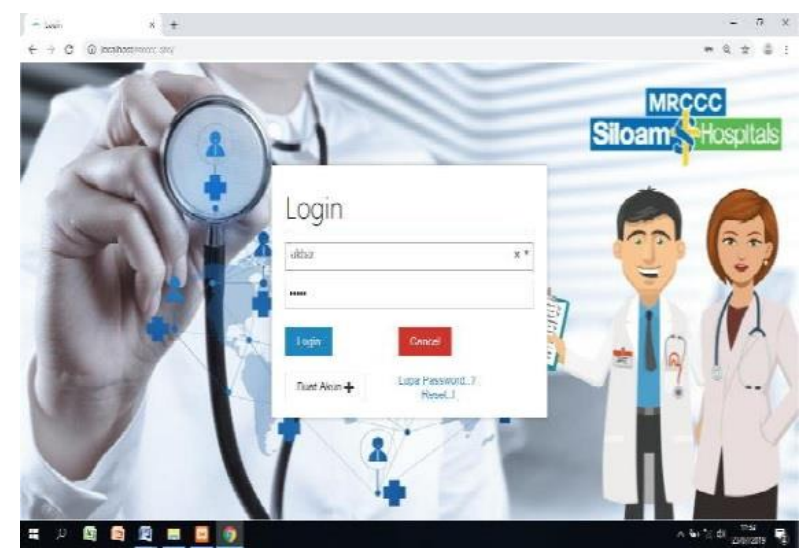

Gambar 5. Halaman Login

Pada Gambar 5 halaman login pengguna harus memilih username yang digunakan dan 
memasukkan password yang tepat. Tersedia menu untuk membuat username dengan melengkapi identitas yang dikonfirmasi oleh pimpinan/kepala departemen. Jika pengguna lupa password yang digunakan, maka tersedia juga menu untuk mereset password dengan mencantumkan tanggal lahir pengguna.

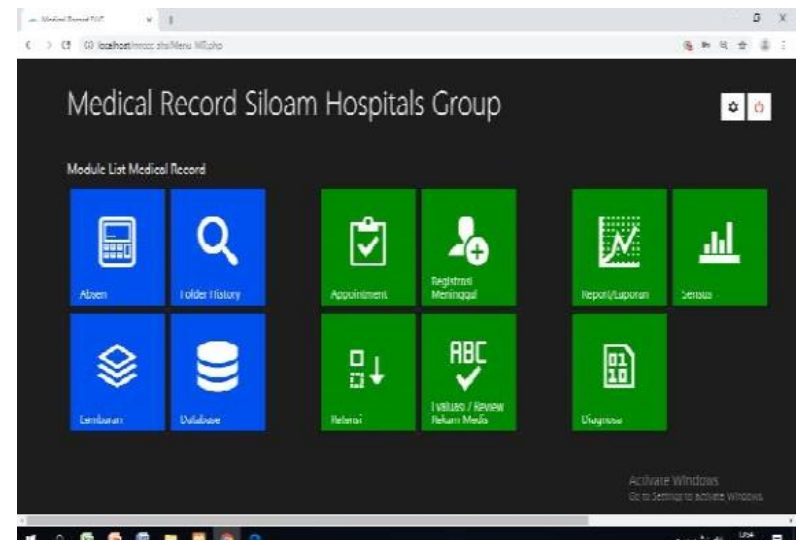

Gambar 6. Halaman Menu Utama

Pada halaman menu utama ini seperti pada gambar 6 merupakan tampilan awal program. Pengguna melakukan login dan terdapat beberapa menu lainnya yang dapat diakses oleh pengguna.

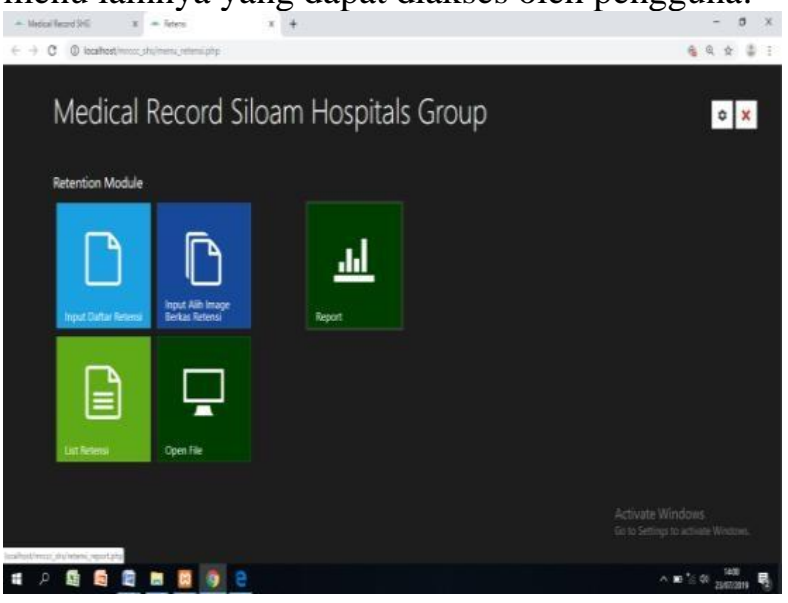

Gambar 7. Halaman Modul Retensi

Pada gambar 7 menjelasakan jika pengguna klik menu retensi pada menu utama maka akan tampil tampilan menu-menu pada modul retensi.Terdapat pilihan menu antara lain menu input daftar retensi, menu input alih image berkas retensi, menu list retensi, menu open file dan menu report.

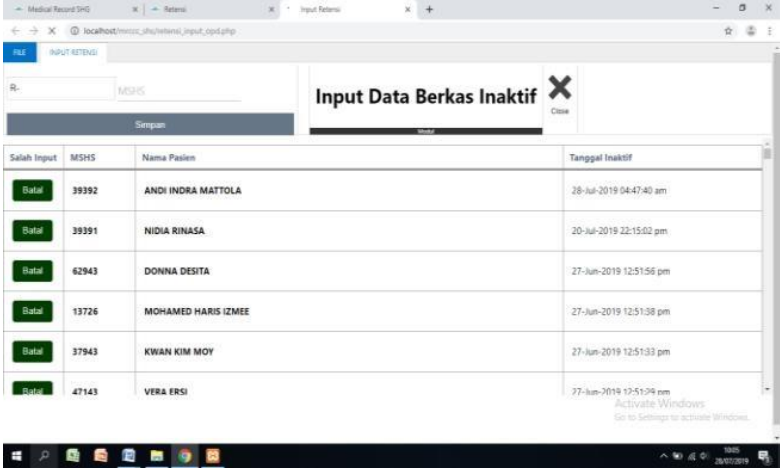

Gambar 8 Halaman input retensi

Pada gambar 8 terdapat modul input daftar retensi, jika pengguna klik modul tersebut akan keluar menu tampilan input retensi seperti yang telihat pada gambar 9. Pada tampilan input retensi user bisa melihat nama pasien yang sudah melewati batas untuk retensi yakni 5 tahun setelah kunjungan terakhir, kemudian dari menu ini user mendapatkan medical record dari pasien untuk kemudian akan di alih image kedalam bentuk digital.

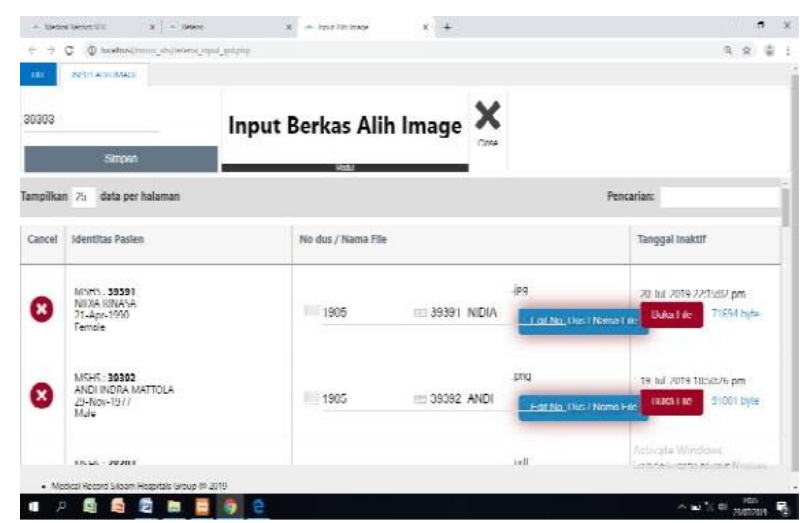

Gambar 9. Halaman Proses Input Alir Images

Pada tampilan menu input alih image yang terlihat seperti gambar 9 terdapat satu text box untuk menginput urutan berkas yang berguna untuk memasukkan file retensi baru ketika tombol save diklik, kemudian terdapat icon silang yang berfungsi untuk menghapus file, kemudian ada icon edit No dus / Nama File yang berfungsi untuk mengedit No dus / Nama File, setelah itu ada icon buka file untuk memeriksa file yang sudah dimasukan. 


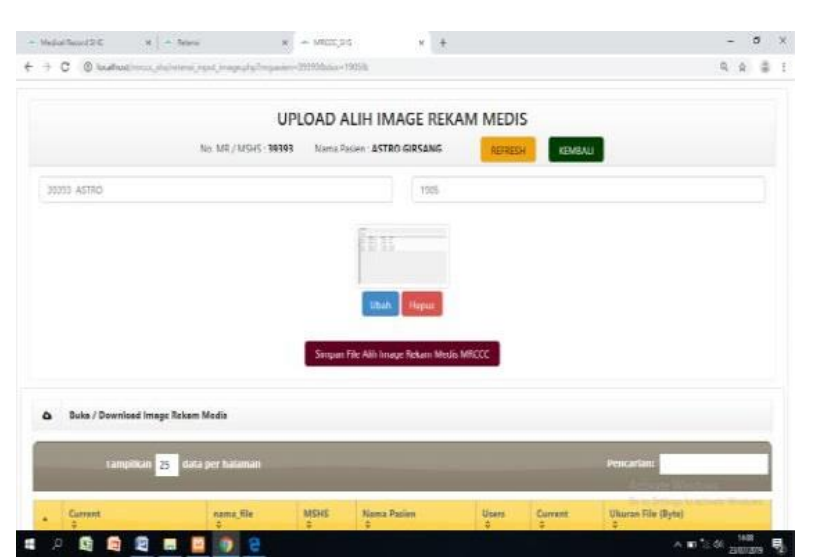

Gambar 10. Hasil Input Gambar Retensi

Setelah klik save pada menu input alih image yang terlihat pada gambar 10 maka akan muncul tampilan upload upload alih image seperti pada gambar, di sini akan terlihat nama pasien dan nomor medical record, selanjutnya user menscan berkas yang akan dialih image untuk diubah kefile digital dengan cara mengupload file yang sudah di scan.

\section{Kesimpulan}

Berdasarkan hasil analisa yang telah diuraikan pada bab-bab sebelumnya, maka dapat disimpulkan sebagai berikut:

a. Penelitian ini berhasil membuat sistem retensi dan alih image rekam medis inaktif pada rumah sakit khusus kanker mrccc siloam semanggi sehingga mempermudah mengatur file-file yang ada dan kemudian di alih imagekan.

b. Mengimplementasikan sistem retensi dan alih image rekam medis inaktif pada Rumah Sakit Khusus Kanker MRCCC Siloam Semanggi dengan cara mengakses url pada komputer admin.

c. Pengembangan pada sistem retensi rumah sakit ini dibutuhkan untuk mencerminkan rumah sakit yang unggul dan modern.

\section{Referensi}

Alatas, H. (2013). "Responsive Web Design dengan PHP \& Bootstrap. Yogyakarta: Lokomedia.

Arief, M. R. (2011). Pemrograman Web Dinamis Menggunakan Php dan Mysql. Yogjakarta: Andi.

Faridl, M. (2015). Fitur Dahsyat Sublime Text 3. Surabaya: LUG STIKOM.

Prasetio, A. (2012). Buku Pintar Pemrograman Web. Jakarta: Mediakita.

Puspitasari. (2011). Pemrograman Web Database dengan PHP \& MySQL. Jakarta: Skripta.

RI, D. K. (2006). Pedoman Organisasi Rumah Sakit di Lingkungan Depkes.
1045/Menkes/PER/XI/2006.

Jakarta:

Pemerintah Republik Indonesia.

RI, D. K. (2008). Peraturan Menteri Kesehatan RI. Jakarta: Departemen Kesehatan Republik Indonesia.

RI, U.-u. (1997). Pelayanan Medik. Jakarta: Departemen Kesehatan Republik Indonesia.

Sutabri, T. (2004). Analisis Sistem Informasi. Jogjakarta: Andi Offset.

Sya'ban, W. (Yogyakarta). Build Your Blogger XML Template. 2010: Andi. 